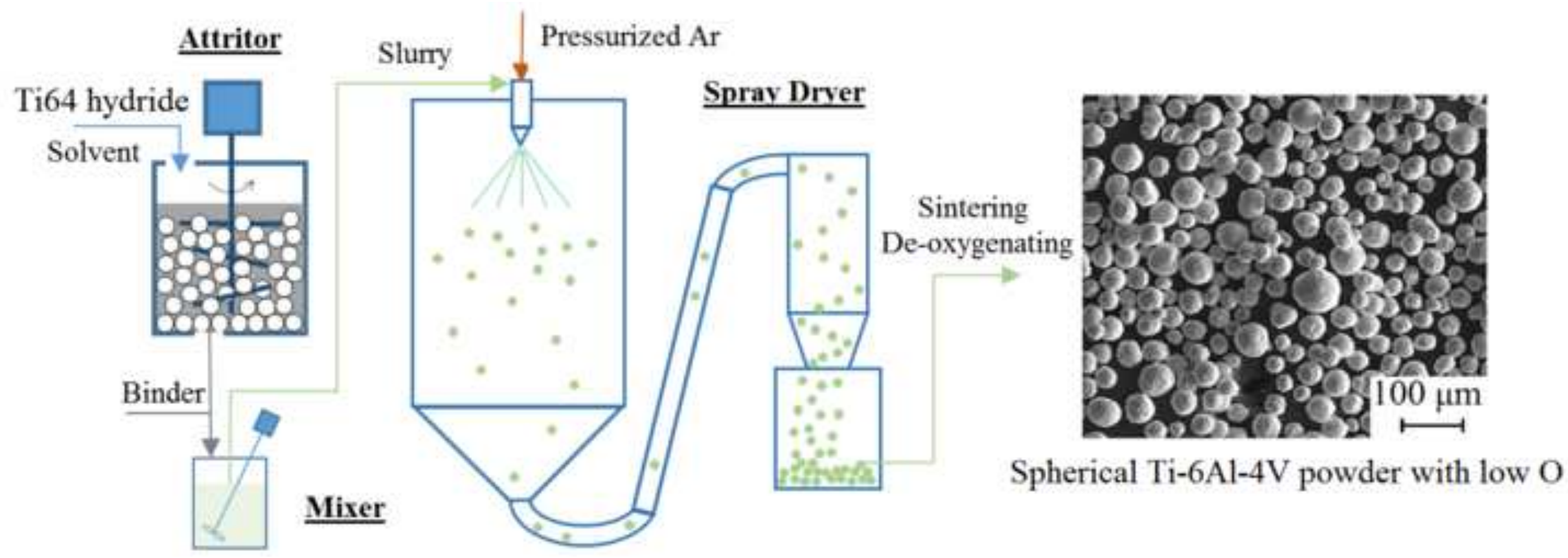




\title{
A Novel Method for Production of Spherical Ti-6Al-4V Powder for Additive
}

\section{Manufacturing}

\author{
Pei Sun ${ }^{a}$, Z. Zak Fang ${ }^{a, *}$, Yang Xia ${ }^{a}$, Ying Zhang ${ }^{a, b}$ and Chengshang Zhou ${ }^{b}$ \\ ${ }^{a}$ Department of Metallurgical Engineering, the University of Utah, Salt Lake City, Utah \\ 84112, USA \\ ${ }^{\mathrm{b}}$ On leave from Institute of Process Engineering, Chinese Academy of Science (IPE, CAS) \\ * Corresponding author e-mail address: zak.fang@utah.edu
}

\section{Introduction}

Titanium is known as a wonder metal because of its properties including high strength to density ratio, excellent corrosion resistance, and biocompatibility. However, the use of Ti in the industry is extremely limited because it is prohibitively expensive for many consumer applications. Powder metallurgy (PM) has long been suggested as a low cost manufacturing alternative to traditional wrought methods [1]. PM methods include die pressing and sintering, metal injection molding (MIM), and hot isostatic pressing (HIP), which have advantages over the traditional wrought method with respect to the efficiency of material utilization due to its nearnet-shape (NNS) capability. In the most recent decade, with the advent of additive manufacturing (AM) technologies, the manufacturing of Ti components using selective laser melting (SLM) and electron beam melting (EBM) techniques emerged as one of the most important areas of $\mathrm{Ti}$ manufacturing [2-4]. All NNS methods including AM, MIM, and HIP use Ti or Ti alloy powders to make bulk materials and components. Needless to say, the quality and performance of Ti alloy and components depends strongly on the quality and cost of the Ti alloy powders that are used. First of all, the powders must meet the stringent requirements of chemical compositions for $\mathrm{Ti}$ 
alloys including low oxygen content. Typical specifications for Ti-6Al-4V alloy mandates that the oxygen content of finished Ti products to be lower than $0.2 \mathrm{wt} . \%$, which has been very challenging for PM Ti.

In general, the oxygen content of Ti powder is inversely proportional to the particle sizes [5]. In other words, the smaller the particle size the higher the oxygen content. Secondly, most NNS methods mentioned above require powder to have excellent flowability, which dictates that the powder must have spherical shape and the particle sizes must be reasonably large. The flowability of the powder decreases with a decrease in particle size. Furthermore, the powders must have good apparent density and tap density, which also affect the density and uniformity of manufactured parts. In short, spherical Ti alloy powder with low oxygen and good flowability is in high demand. Unfortunately, high quality spherical $\mathrm{Ti}$ alloy powders that meet the requirements of NNS manufacturing as described above, especially powders for AM Ti are all very costly and in short supply, which hinders the development of Ti for broad applications using AM or any other advanced manufacturing techniques. Therefore, a strong need exists in the AM as well as conventional PM industries to develop low cost methods for the production of spherical low oxygen $\mathrm{Ti}$ alloy powders that meet all requirements for chemical composition and physical properties.

Conventional spherical $\mathrm{Ti}$ powder production methods include the plasma rotating electrode process (PREP), gas atomization (GA), and plasma atomization (PA) [6]. The PREP powder has very high purity and very spherical shape. However, the size of PREP powder is also typically coarser (e.g. 50-350 $\mu \mathrm{m}$ [7]) and the size distribution wider than desired for AM or MIM applications. Finer spherical powder can, however, be produced via GA and PA methods. Typical particle sizes of GA and PA Ti alloy powders range from 10 to $300 \mu \mathrm{m}$ [6]. Although 
atomized powder can be classified to produce desired size cuts, classification reduces the yield of usable size cuts, further increasing the cost of the materials. In general, satellite formation is difficult to avoid in GA techniques, which are detrimental for achieving good flowability [5]. Internal voids within individual particles that contain trapped argon are another concern for GA powders. Most of the atomizing techniques depend on using high quality mill products, such as wires or rods, which have high built-in costs, making it difficult to reduce the cost of high quality powders. The price of spherical Ti-6Al-4V powder is in the range of one to five hundred dollars per kilogram [8], and varies depending on particle size, impurity level, and quantity. In short, making high quality low cost spherical Ti alloy powder has become a glaring technology challenge for the Ti manufacturing industry. There is no single process to date that can produce Ti and Ti alloy powders with all the required characteristics: spherical, desired size range (from a few to 40 microns or from 40 to $100 \mu \mathrm{m}$ in size), low oxygen $(<0.2 \mathrm{wt} . \%)$, and low cost. The objective of this research is to develop such a process to achieve all of the above.

There have been some reported research efforts on making spherical Ti powder more affordable. Among those efforts, plasma-spheroidization has been used commercially [9]. During plasma spheroidization, the metal powder is melted by a plasma torch and forms molten droplets, which solidify to form spherical solid powder before reaching the bottom of the reactor chamber [10]. Plasma-spheriodized particles typically have a very spheroidal shape, similar to other atomized powder $[11,12]$. Another example is a continuous method during which low-cost $\mathrm{Ti}$ sponge or electrolytically produced $\mathrm{Ti}$ and alloy powders were fed through a plasma transferred arc torch to make spherical alloy powder [13]. In addition to spheroidizing or producing particles in the molten state, there are reports on modifying particle shape in the solid state by mechanical 
means $[14,15]$. The flowability of irregularly shaped powders was reportedly improved by removing sharp angles on the particles through high-speed blending or high sheer milling.

In this paper, a new process is designed and demonstrated. The new process combines granulation and sintering to form solid spherical particles. The new process also minimizes the oxygen content in the powder by using a low temperature molten salt process to de-oxygenate the Ti alloy powder. This granulation-sintering-deoxygenation (GSD) process is also inherently low-cost. The current paper describes the process, as well as elaborating the fundamentals behind the process, especially the principles of controlling oxygen content.

\section{Experimental}

The raw material used in this study was -200 mesh Ti-6Al-4V hydride powder purchased from Reading Alloys, an Ametek company. This powder was produced from Ti-6Al-4V scrap through cleaning, hydrogenating, milling and sizing steps. It is noted that blended elemental powder can be used as raw material as well. As-received -200 mesh Ti-6Al-4V hydride powder was first ball-milled in a solvent to reduce the particle sizes to less than $10 \mu \mathrm{m}$. A thermoplastic binder of about 2 wt.\% was added to aid the formation of granules. After ball-milling, the slurry was fed into a spray dryer (Buchi Mini Spray Dryer B290) and was dried with Ar gas to form spherical granules consisting of fine Ti-6Al-4V hydride particles. The granules were sieved, and the size cut of $-140+400$ mesh $(37-106 \mu \mathrm{m})$ was collected for subsequent processing. Unwanted granules can be returned to the slurry.

The spherical granules were thermally debinded in the temperature range of $200-400{ }^{\circ} \mathrm{C}$ for 10 hours and sintered at $1200{ }^{\circ} \mathrm{C}$ for 4 hours in argon atmosphere in a tube furnace. The flow rate of argon during sintering was 1 liter per minute. The pressure during sintering was controlled slightly above atmospheric pressure to let Ar flow through the furnace tube. An inorganic 
separator was used during debinding and sintering to prevent granules from sintering to each other. The separator must have the following characteristics: it must be able to survive the high temperature of sintering; it must not react with the Ti alloy powder during sintering; and there must be a way to separate the "separator" from the sintered granules after sintering. Calcium oxide $(\mathrm{CaO})$ powder with $99.9 \%$ purity was used as the separator in this study. After sintering, $\mathrm{CaO}$ was leached with dilute hydrochloride acid, washed with water, and then dried in air at room temperature. The sintered spherical Ti-6Al-4V powder was de-oxygenated with calcium metal. The de-oxygenation was conducted in a tube furnace at $750{ }^{\circ} \mathrm{C}$ for 12 hours in flowing Ar. The powder after de-oxygenation was leached using dilute $\mathrm{HCl}$ acid and then was washed with water. Finally, the powder was dried in air at room temperature. The entire process as described above is schematically illustrated in Figure 1. It is believed that the GSD process requires much less energy than other atomizing methods during which Ti alloys need to be melted. However, a detailed analysis of the process energy is yet to be carried out. In the GSD process, $\mathrm{Ca}, \mathrm{CaO}$ and $\mathrm{HCl}$ are consumed, and $\mathrm{CaCl}_{2}$ would be the main by-product, which can be reconverted to $\mathrm{Ca}$, $\mathrm{CaO}$ and $\mathrm{HCl}$, if desired.

The oxygen/nitrogen/hydrogen contents in the powder were determined by using a LECO TCH 600 , and the carbon content was analyzed by using a LECO C/S 230. The concentrations of metallic elements in the powder were analyzed by using an inductively coupled plasma-atomic emission spectrometer (ICP-AES). All measurements were taken three times, and the average is reported.

\section{Results}

Figure 2a shows that the particle size of hydrogenated Ti-6Al-4V scrap was reduced to less than $10 \mu \mathrm{m}$ after ball milling for 100 minutes. The spray-dried granules are shown in Figure $2 \mathrm{~b}$, 
having a very good spherical shape. The sintered granules are shown in Figure 2c, demonstrating that they inherit the desired spherical shape of the spray dried granules. The cross-section of the sintered granules is shown in Figure 2e. There are no obvious internal voids in the as-sintered granules. According to Figures $2 \mathrm{~d}$ and $\mathrm{f}$, the particle size of the final de-oxygenated Ti-6Al-4V powder ranges from 20 to $90 \mu \mathrm{m}$. The powder can be further classified into different size cuts for different applications (i.e. $20-45 \mu \mathrm{m}$ for SLM, $45-90 \mu \mathrm{m}$ for EBM, and $<45 \mu \mathrm{m}$ for MIM). It is noted here that the processing parameters of spray drying can be adjusted to maximize yield of various size cuts for different applications. The micrograph of the cross section of the final powder (Figure 2e) reveals that the particles were fully densified and have fine lamellar microstructure. The true density of the material was measured using a pycnometer, which shows that there is only $\sim 0.5$ vol. $\%$ porosity in the final products (Table 1 ). The measured flowability, apparent density and tap density are also listed in Table 1 .

Table 2 lists the chemical composition of the powder at different stages during the GSD process, and shows that the final spherical Ti-6Al-4V powder meets the requirements of AMS4998 for chemical composition. The oxygen content of the powder is even lower than the requirement of AMS. In fact, the oxygen content in the final product powder can be tailored in the range between $0.08-0.20 \mathrm{wt} . \%$, if so desired. Understandably, oxygen content in the powder changed drastically throughout the multiple steps of the process. Oxygen content of the powder increased during milling and sintering, while it decreased during the de-oxygenation step, designed for that purpose. The issue of controlling oxygen content in the powder is further discussed below.

\section{Discussion}

4.1 Oxygen pick-up during milling 
Oxygen content of as-milled powder depends directly on the particle sizes in the as-milled condition. As shown in Figure 3, the oxygen content in the powder during milling is linearly dependent on the specific surface area. In this research, the temperature of milling was controlled at room temperature by flowing water through the cooling jacket on the attritor. At this temperature, the oxygen picked up during milling is unable to diffuse into the bulk of the particles, thus the increased oxygen content would only accumulate on the surface of particles. Assuming that a uniform layer of $\mathrm{TiO}_{2}$ forms on the surface of all particles, the oxygen weight percentage in the powder can be expressed as:

$$
O_{\text {total }}=O_{\text {bulk }}+O_{\text {surface }}=O_{\text {bulk }}+a \times t \times \rho_{\text {TiO }_{2}} \times O_{\text {TiOO }_{2}}=O_{\text {bulk }}+1.69 \times 10^{8} \mathrm{ta}
$$

where $\mathrm{a}$ is the specific surface area of the powder, $\mathrm{t}$ is the thickness of the $\mathrm{TiO}_{2}$ layer, $\rho_{\mathrm{TiO}_{2}}$ is the density of $\mathrm{TiO}_{2}$, and $O_{\mathrm{TiO}_{2}}$ is the oxygen weight percentage in $\mathrm{TiO}_{2}$. By comparing eq. (1) with the equation of the linear regression line in Figure 3, the thickness of the oxide layer was calculated to be $3.8 \mathrm{~nm}$ and the bulk oxygen content was $0.32 \%$. It should be noted, however, if the oxide on the surface is non-stoichiometric $\mathrm{TiO}_{\mathrm{x}}$, then the oxide layer on the surface would be thicker than $3.8 \mathrm{~nm}$.

\subsection{Oxygen pick-up during sintering}

Oxygen content also increased significantly during sintering in this study. This is a surprising result because the sintering was conducted in inert atmosphere. However, as mentioned earlier, $\mathrm{CaO}$ was used as a separator during sintering. $\mathrm{CaO}$ was thought to be inert with regard to $\mathrm{Ti}$ because calcium is a well-known reducing agent for Ti oxide [17-19], since calcium oxide is more thermodynamically stable than titanium oxide according to the Ellingham diagram. In other words, the reaction of $\mathrm{Ti}+2 \mathrm{CaO} \rightarrow \mathrm{TiO}_{2}+2 \mathrm{Ca}$ is thermodynamically unfavorable. However, the oxygen content did increase from $2.20 \mathrm{wt} . \%$ to $3.56 \mathrm{wt} . \%$ during the de-binding and sintering 
experiments of this study, as shown in Table 2 . The only source of oxygen pick-up for the titanium alloy in the system was the $\mathrm{CaO}$ powder. This apparent contradicting fact is explained as follows.

Titanium has significant solubility for oxygen as a solid solution. The chemical potential of oxygen in titanium as a function of oxygen content is plotted in Figure 4 [19], which reveals that the oxygen chemical potential in the non-stoichiometric $\mathrm{TiO}_{2-\mathrm{x}}$ or $\mathrm{Ti}-\mathrm{O}$ solid solution is lower than that in $\mathrm{TiO}_{2}$. And also, at $1200{ }^{\circ} \mathrm{C}$ in flowing Ar, calcium metal would form and evaporate depending on the vapor pressure of oxygen. When calcium is in its gas state, the formation of $\mathrm{CaO}$ reaction can be written as $2 \mathrm{Ca}(\mathrm{g})+\mathrm{O}_{2}=\mathrm{CaO}(\mathrm{s})$. The standard free energy change of formation of $\mathrm{CaO}$ is expressed by eq. (2):

$$
\Delta G_{C a O}^{o}=R T \ln \left(\frac{P_{O_{2}}}{P^{o}}\right)\left(\frac{P_{C a}}{P^{o}}\right)^{2}=R T \ln \left(\frac{P_{O_{2}}}{P^{o}}\right)+2 R T \ln \left(\frac{P_{C a}}{P^{o}}\right)
$$

where $\mathrm{P}^{\mathrm{o}}$ denotes $1 \mathrm{~atm}$. The standard free energy change for the formation of $\mathrm{CaO}$ from calcium vapor at different partial pressures of calcium was added to Figure 4.

Taking Ti with 0.03 wt.\% as an example, it would react with calcium oxide to form Ti-O solid solution with a higher oxygen content at $1200{ }^{\circ} \mathrm{C}$ under 1 atm of calcium pressure, and the oxygen content in $\mathrm{Ti}$ would increase and reach equilibrium at a value between 0.03 to $0.34 \mathrm{wt} \%$ according to Figure 4. If the calcium vapor pressure decreases to $10^{-2}$ atm, $\mathrm{Ti}$ would dissolve more oxygen and equilibrate with $\mathrm{CaO}$ at an oxygen content of $\sim 3.57$ wt.\%. Therefore, the equilibrium oxygen concentration in Ti metal is higher under a lower calcium vapor pressure. In other words, a low partial pressure of calcium vapor (e.g. in vacuum and in flowing inert gas) favors oxidation of titanium metal in the $\mathrm{Ti}-\mathrm{CaO}$ system. As a result, in the experiment as described earlier in flowing Ar, the Ti-6Al-4V powder picked up a significant amount of oxygen (1.36 wt.\%) during sintering at $1200{ }^{\circ} \mathrm{C}$, and it equilibrated with $\mathrm{CaO}$ at the oxygen 
concentration of $3.56 \mathrm{wt} \%$. This explains the observed increase of oxygen content during sintering in the presence of $\mathrm{CaO}$.

\subsection{Oxygen reduction during de-oxygenation}

Oxygen content decreased during the de-oxygenation, as it is designed to do. The oxygen content of sintered Ti-6Al-4V particles must be below 0.18 wt. $\%$ to meet the specifications of AMS 4998 for Ti-6Al-4V powder. Calcium is known to be an effective reducing agent to reduce not only $\mathrm{TiO}_{2}$ but also $\mathrm{Ti}$ (alloy) powder with high oxygen content [20-22]. The calciothermic reduction is usually conducted above $900{ }^{\circ} \mathrm{C}$ (i.e., above the beta transus of titanium and the melting point of calcium). In 1988, the RMI Company filed a patent for the de-oxygenation of titanium in the forms of milled or finished parts, scrap metal, and powder [22]. During this process solid $\mathrm{Ti}$ is de-oxygenated in molten $\mathrm{Ca}$, which is thus termed as de-oxygenation in solid state (DOSS) process, within the operating temperature range of 900-1000 ${ }^{\circ} \mathrm{C}$ [22]. The DOSS process cannot be directly applied for de-oxygenation of the spherical Ti powder because the spherical shape would be destroyed during milling if strong bonding is formed between the particles during the de-oxygenation process, which would occur when the Ti alloyed powder is exposed to temperatures above $900{ }^{\circ} \mathrm{C}$. Therefore, the challenge for the de-oxygenation of spherical Ti powder is to reduce the oxygen content without forming strong bonding between the particles.

In order to eliminate or minimize the bonding between particles during de-oxygenation, the de-oxygenation temperature has to be significantly lower than $900{ }^{\circ} \mathrm{C}$. J.M. Oh et al. reduced oxygen content in Ti powder from 0.22 wt.\% to $0.10-0.15$ wt. $\%$ in the temperature range of 700 - $830{ }^{\circ} \mathrm{C}$ by using $\mathrm{Ca}$ vapor [21]. However, in this temperature range, the rate of de-oxygenation is very slow because the vapor pressure of $\mathrm{Ca}$ at solid state is extremely low. In this work, a low 
temperature molten salt process (LTMS) is applied to de-oxygenate the spherical Ti powder [23]. During LTMS, a eutectic salt consisting of $\mathrm{CaCl}_{2}$ (melting point $772{ }^{\circ} \mathrm{C}$ ) and $\mathrm{KCl}$ (melting point $770{ }^{\circ} \mathrm{C}$ ) was used with calcium metal. The eutectic salt has a melting point at $690{ }^{\circ} \mathrm{C}$. When the de-oxygenation is carried out at $750{ }^{\circ} \mathrm{C}$, the salt is in its molten state, which greatly facilitates the transport of the reducing agent and the reaction between $\mathrm{Ca}$ and oxygen [23]. During the deoxygenation process, the oxygen atoms diffuse to the Ti-6Al-4V particle surface to form calcium oxide. Furthermore, according to Figure 4, in addition to the benefit of minimizing bonding between particles, another reason for using the low temperature de-oxygenation process is that the equilibrium oxygen content in $\mathrm{Ti}$ is lower at a lower temperature; thus a lower oxygen content can be achieved. As shown earlier, after being de-oxygenated at $750{ }^{\circ} \mathrm{C}$ for 12 hours, the oxygen content in the Ti-6Al-4V spherical powder was reduced to $0.10 \mathrm{wt} \%$.

It is apparent that the surface of particles formed by the GSD method is not as smooth as that of PREP, GA or PA powders, since Ti particles do not go through a molten state during the GSD process, and melting/solidification can produce very smooth surfaces. However, it should be noted that spherical titanium powder is usually recycled after printing, and the surface becomes

rougher with repeated cycling [24]. The surface quality of powder by the GSD method is close to or better than that of reused spherical Ti-6Al-4V powder in the AM process, indicating GSD powder meets the requirement of surface quality for AM applications.

\section{Summary}

A novel method that synergistically combines granule spheroidization, sintering, and deoxygenation into one integrated process for producing low-cost spherical Ti-6Al-4V powder is demonstrated. The spherical powder produced using the GSD method has controlled particle size, size distributions and low oxygen content. The powder can be used for additive manufacturing, 
cold spraying, metal injection molding, hot isostatic pressing, press and sintering, as well as other Ti manufacturing processes. This method is also applicable for producing other spherical titanium alloy or other metal alloy powders such as nickel based super alloy powders and stainless steel powders.

\section{Acknowledgement}

The authors acknowledge partial financial support by ARPA-E, U.S. Department of Energy under contract DE-AR0000420. The first author also acknowledges the help of Mr. Yanlu Zhai for spray-drying. The authors thank Dr. Mark Koopman for proof-reading this manuscript.

\section{References}

[1] Z. Z. Fang, P. Sun, Pathways to optimize performance/cost ratio of powder metallurgy titanium - a perspective, Key Eng. Mater. 520 (2012) 15-23.

[2] I. Gibson, D.W. Rosen, B. Stucker, Additive manufacturing technologies: rapid prototyping to direct digital manufacturing, Springer, New York, 2010.

[3] D.D. Gu, W. Meiners, K. Wissenbach, R. Poprawe, Laser additive manufacturing of metallic components: materials, processes and mechanisms, Int. Mater. Rev. 57 (2012) 133-164.

[4] L.E. Murr, S.M. Gaytan, D.A. Ramirez, E. Martinez, J. Hernandez, K.N. Amato, P.W.

Shindo, F.R. Medina, R.B. Wicker, Metal fabrication by additive manufacturing using laser and electron beam melting technologies, J. Mater. Sci. Tech. 28 (2012) 1-14.

[5] C.G. McCracken, C. Motchenbacher, D.P. Barbis, Review of titanium powder production methods, Int. J. Powder Metall. 46 (2010) 19-26.

[6] C.F. Yolton, F.H. Froes, Conventional titanium oowder production, in: M. Qian, F.H. Froes (Eds.), Titanium powder metallurgy: science, technology and applications, Elsevier, Waltham, MA, 2015, pp. 51-67.

[7] P.R. Roberts, The production of PREP titanium powder, Advances in powder metallurgy: proceeding of the 1989 powder Metallurgy Conference \& Exhibition, San Diego, CA, Metal Powder Industries Federation, 1989, pp. 427-438.

[8] F.H. Froes, Titanium powder metallurgy: a review-part 1, Adv. Mater. Proc. 170 (2012) 1622.

[9] Tekna Plasma Systems Inc., http://tekna.com/equipment-spheroidization-nanosynthesisdeposition/spheroidization-equipment/, access date 6/11/2016.

[10] M. Boulos, Plasma power can make better powders, Met. Powder Rep. 59 (2004) 16-21.

[11] K. Araci, D. mangabhai, K. Akhtar, Production of titanium by the armstrong process, in: M. Qian, F.H. Froes (Eds.), Titanium powder metallurgy: science, technology and applications, Elsevier, Waltham, MA, 2015, pp. 149-162.

[12] D.P. Barbis, R.M. Gasior, G.P. Walker, J.A. Capone, T.S. Schaeffer, Titanium powders from the hydride-dehydride process, in: M. Qian, F.H. Froes (Eds.), Titanium Powder Metallurgy: Science, Technology and Applications, Elsevier, Waltham, MA, 2015, pp. 101-105. 
[13] J.C. Withers, R.O. Loutfy, Low cost processing to produce spherical titanium and titanium alloy powder, US Patent 8,911,529 B2, 2014.

[14] G. Gai, Y. Yang, L. Jin, X. Zou, Y. Wu, Particle shape modification and related property improvements, Powder Tech. 183 (2008) 115-121.

[15] Y.Y. Sun, S. Gulizia, C.H. Oh, C. Doblin, Y.F. Yang, M. Qian, Manipulation and characterization of a novel titanium powder precursor for additive manufacturing applications, JOM 67 (2015) 564-572.

[16] Advanced Powder \& Coatings Inc., http://advancedpowders.com/our-plasma-atomizedpowders/products/ti-6al-4v-titanium-alloy-powder/\#15-45 m, access date 6/11/2016.

[17] R. Suzuki, S. Inoue, Calciothermic reduction of titanium oxide in molten $\mathrm{CaCl}_{2}$, Metall. Materi. Trans. B 34 (2003) 277-285.

[18] T.H. Okabe, T. Oda, Y. Mitsuda, Titanium powder production by preform reduction process (PRP), J. Alloys Compd. 364 (2004) 156-163.

[19] K.T. Jacob, S. Gupta, Calciothermic reduction of $\mathrm{TiO}_{2}$ : a diagrammatic assessment of the thermodynamic limit of deoxidation, JOM 61 (2009) 56-59.

[20] C.G. McCracken, J.W. Robison, C.A. Motchenbacher, in: Euro PM2009 - Powder Manufacturing I, Copenhagen, Denmark, 2009, pp. 187-192.

[21] J.M. Oh, B.K. Lee, C.Y. Suh, S.W. Cho, J.W. Lim, Preparation method of Ti powder with oxygen concentration of <1000 ppm using Ca, Powder Metall. 55 (2012) 402-404.

[22] R.L. Fisher, Deoxidation of titanium and similar metals using a deoxidant in a molten metal Carrier, U.S. Patent 4,923,531, 1990.

[23]Z.Z. Fang, Y. Xia, P. Sun, Y. Zhang, PCT App. No. PCT/US15/30669, 2015.

[24]H.P. Tang, M. Qian, N. Liu. X.Z. Zhang, G.Y. Yang, J. Wang, Effect of powder reuse times on additive manufacturing of Ti-6Al-4V by selective electron beam melting, JOM 67(2015) 555563. 


\section{Figure Captions}

Figure 1. Flow chart of the process for making spherical Ti-6Al-4V powder from scrap.

Figure 2. SEM micrograph of (a) as-milled Ti-6Al-4V hydride scrap powder, (b) spray-dried granules, (c) sintered spherical granules, (d) de-oxygenated spherical Ti-6Al-4V powder and (e) its cross section; (f) particle size distribution of de-oxygenated powder by laser diffraction.

Figure 3. The linear dependence of the oxygen content on the specific surface area of milled Ti6Al-4V hydride scrap powder.

Figure 4. The Ellingham diagram showing the oxygen potential in $\mathrm{Ti}-\mathrm{O}$ with different oxygen contents and $\mathrm{CaO}$ under different partial pressures of calcium.

\section{Table Captions}

Table 1. Physical properties of the final GSD Ti-6Al-4V powder and the plasma-atomized Ti6Al-4V powder.

Table 2. Chemical compositions of Ti-6Al-4V after each step during the GSD process. 
Figure(1)

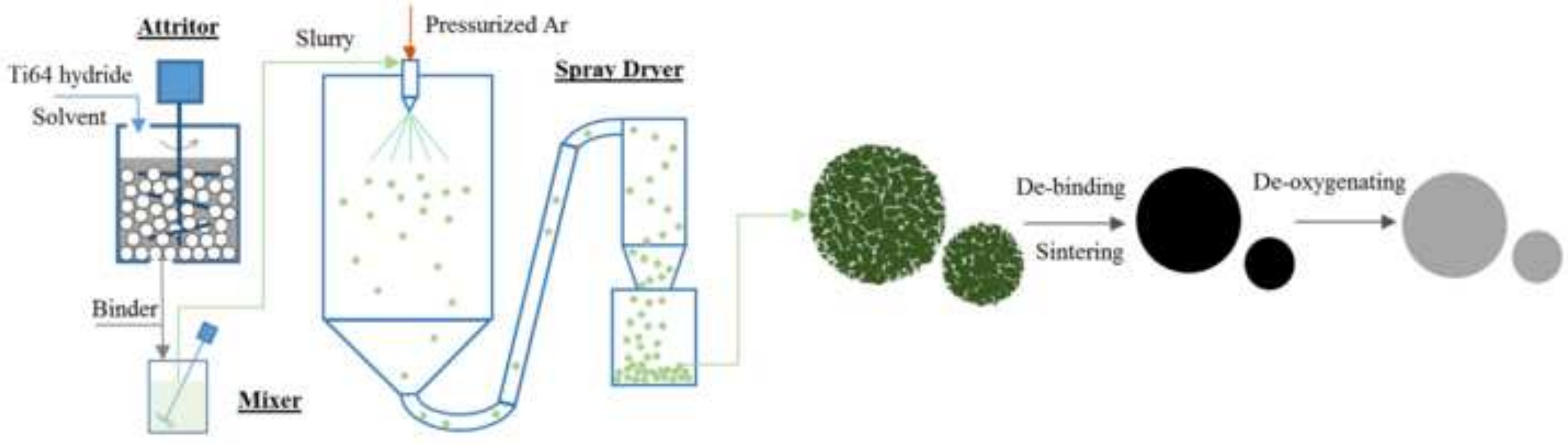



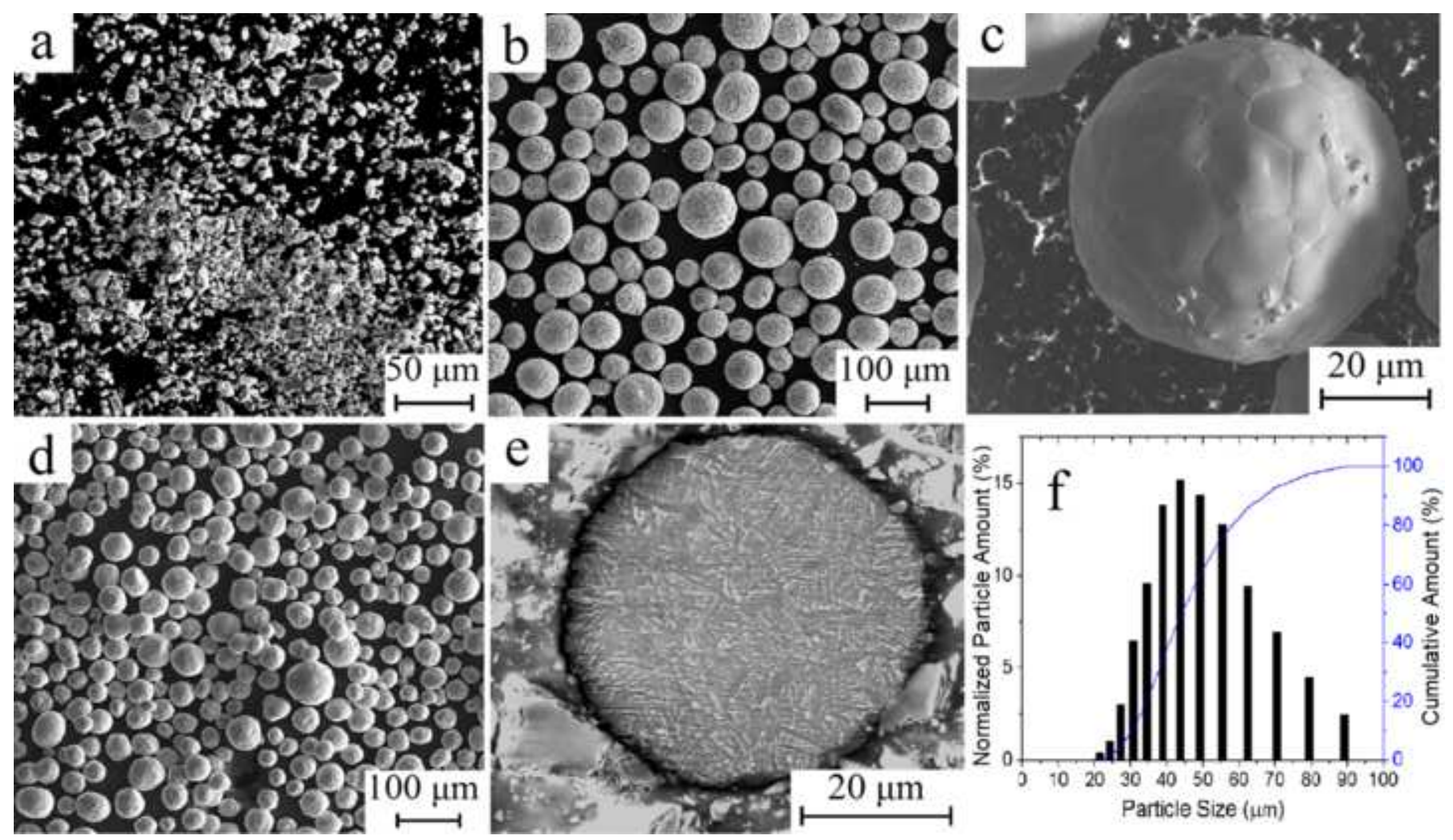


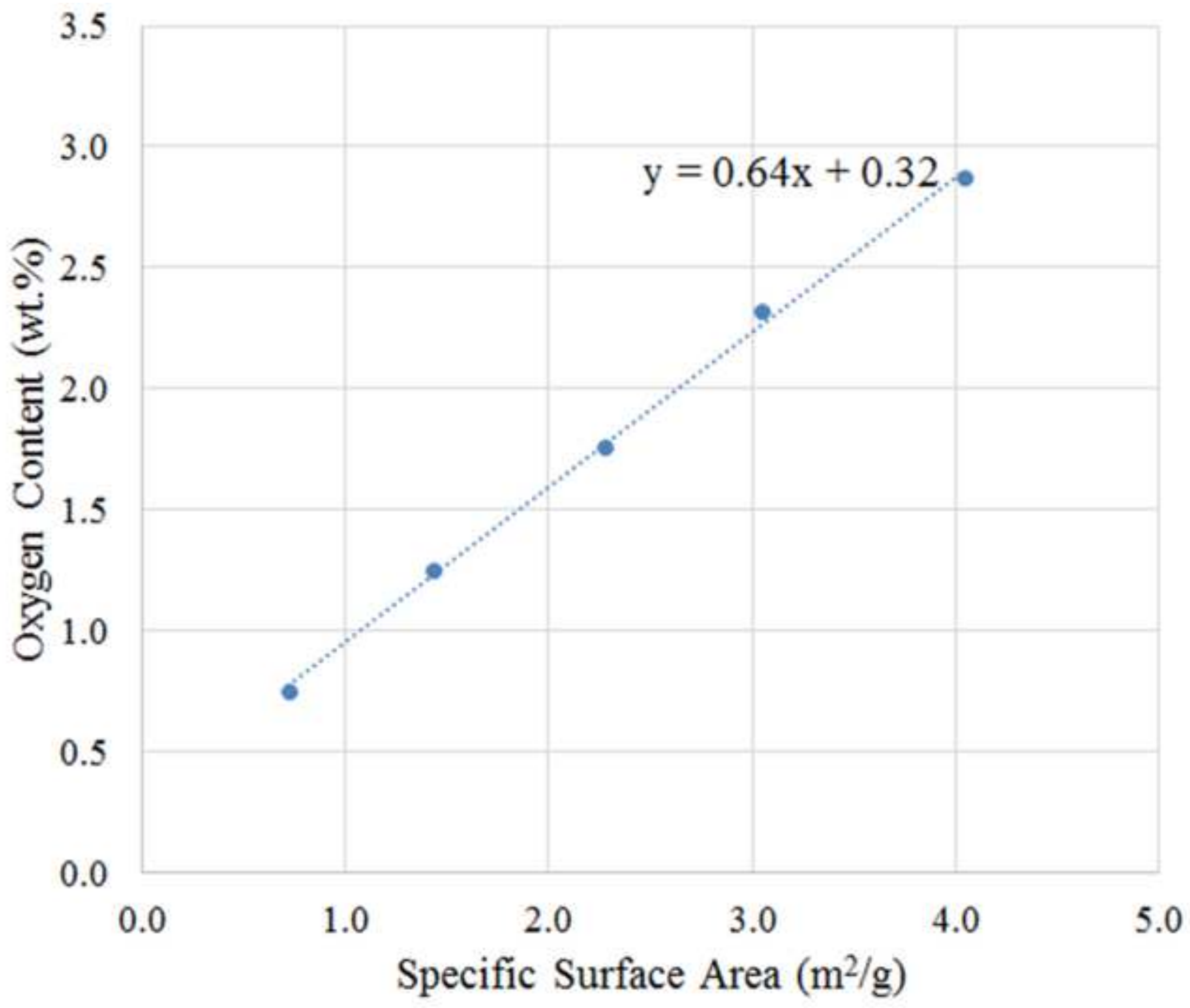




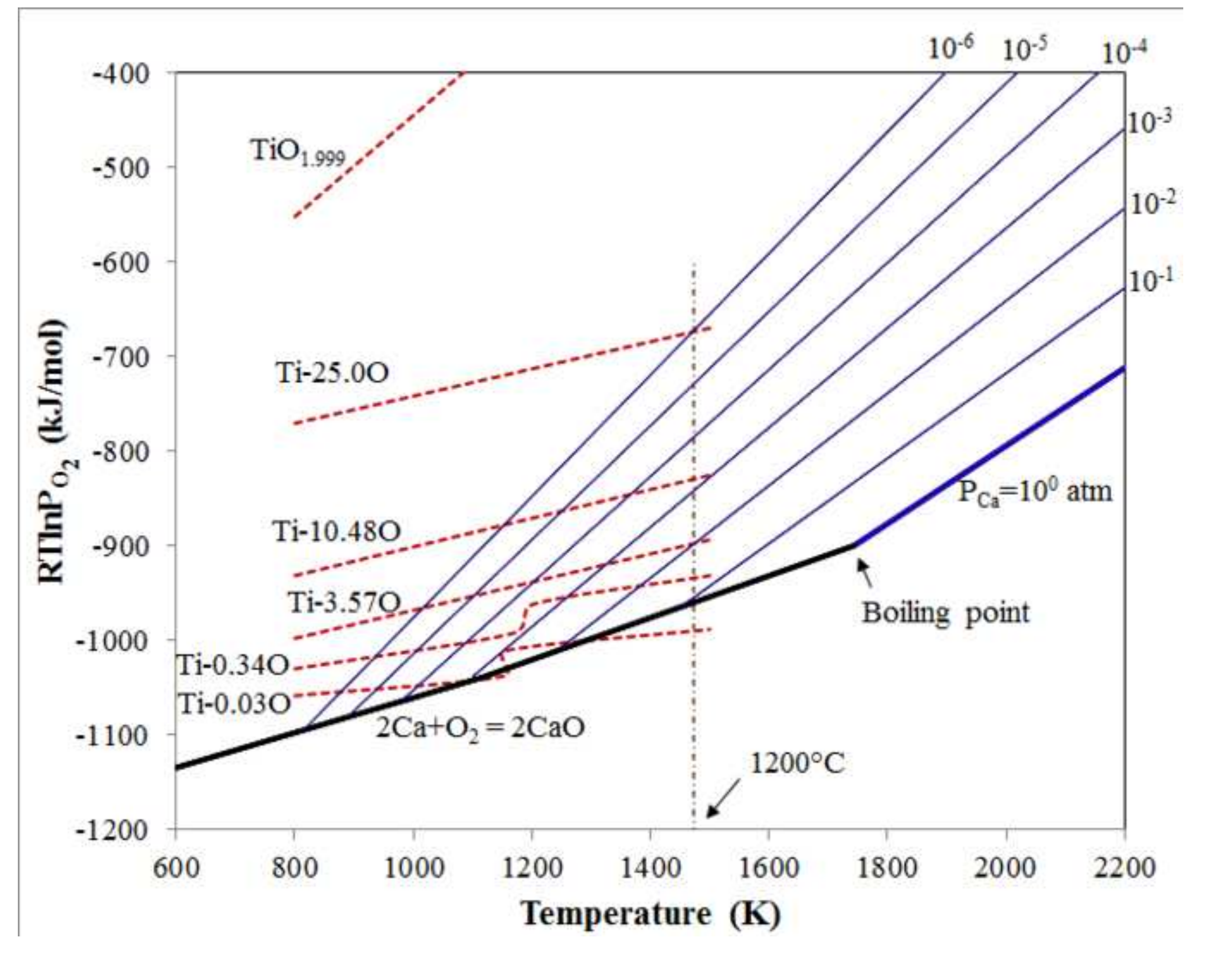

(


Table 1. Physical properties of the final GSD Ti-6Al-4V powder and the plasma-atomized Ti-6Al-4V powder.

\begin{tabular}{ccccc}
\hline & $\begin{array}{c}\text { Flowability } \\
(\mathrm{s} / 50 \mathrm{~g})\end{array}$ & $\begin{array}{c}\text { Apparent } \\
\text { Density }\left(\mathrm{g} / \mathrm{cm}^{3}\right)\end{array}$ & $\begin{array}{c}\text { Tap Density } \\
\left(\mathrm{g} / \mathrm{cm}^{3}\right)\end{array}$ & $\begin{array}{c}\text { True Density } \\
(\%)\end{array}$ \\
\hline GSD powder $(20-45 \mu \mathrm{m})$ & $27.5 \pm 0.3$ & $2.34 \pm 0.02$ & $2.78 \pm 0.02$ & $99.5 \pm 0.1$ \\
PA powder $(15-45 \mu \mathrm{m})[16]$ & 28 & 2.50 & 2.79 & - \\
\hline
\end{tabular}


Table 2. Chemical compositions of Ti-6Al-4V after each step during the GSD process.

\begin{tabular}{|c|c|c|c|c|c|c|c|c|}
\hline (Unit: wt.\%) & $\mathrm{O}$ & $\mathrm{N}$ & $\mathrm{C}$ & $\mathrm{H}$ & $\mathrm{Ca}$ & $\mathrm{Fe}$ & $\mathrm{V}$ & $\mathrm{Al}$ \\
\hline \multirow{2}{*}{ Ti-6Al-4V hydride scrap } & $\begin{array}{c}0.75 \\
\pm 0.03\end{array}$ & $\begin{array}{c}0.03 \\
\pm 0.01\end{array}$ & $\begin{array}{c}0.016 \\
\pm 0.002\end{array}$ & $\begin{array}{c}2.51 \\
\pm 0.02\end{array}$ & $\begin{array}{c}0.061 \\
\pm 0.004\end{array}$ & $\begin{array}{c}0.195 \\
\pm 0.002\end{array}$ & - & - \\
\hline \multirow{2}{*}{ Milled } & $\begin{array}{c}2.20 \\
\pm 0.06\end{array}$ & - & $\begin{array}{c}0.058 \\
\pm 0.004\end{array}$ & - & $\begin{array}{c}0.060 \\
\pm 0.001\end{array}$ & $\begin{array}{c}0.193 \\
\pm 0.005\end{array}$ & - & - \\
\hline \multirow{2}{*}{ Debinded and sintered } & $\begin{array}{c}3.56 \\
\pm 0.04\end{array}$ & $\begin{array}{c}0.03 \\
\pm 0.01\end{array}$ & $\begin{array}{c}0.073 \\
\pm 0.003\end{array}$ & $\begin{array}{c}0.018 \\
\pm 0.002\end{array}$ & $\begin{array}{c}0.075 \\
\pm 0.002\end{array}$ & $\begin{array}{c}0.200 \\
\pm 0.010\end{array}$ & - & - \\
\hline Final GSD Powder & 0.10 & 0.04 & 0.079 & 0.0015 & 0.075 & 0.221 & 3.82 & 5.59 \\
& \pm 0.01 & \pm 0.01 & \pm 0.001 & \pm 0.0010 & \pm 0.001 & \pm 0.008 & \pm 0.09 & \pm 0.06 \\
\hline AMS 4998 & $0.13-$ & 0.04 & 0.1 & 0.012 & - & 0.3 & $3.50-4.50$ & $5.50-6.75$ \\
\hline
\end{tabular}

